\title{
Integrating pest population models with biophysical crop models to better represent the farming system ${ }^{\text {th }}$
}

\author{
Jeremy P.M. Whish ${ }^{\text {a, }}{ }^{,}$, Neville I. Herrmann ${ }^{c}$, Neil A. White ${ }^{b}$, Andrew D. Moore ${ }^{c}$, \\ Darren J. Kriticos ${ }^{\mathrm{c}}$ \\ a CSIRO Sustainable Agriculture National Research Flagship, PO Box 102, Toowoomba, Qld 4350, Australia \\ ${ }^{\mathrm{b}}$ Agri-Science Queensland, Department of Agriculture, Fisheries and Forestry, 203 Tor St, Toowoomba, Qld 4350, Australia \\ c CSIRO Sustainable Agriculture National Research Flagship, GPO Box 1600, Canberra, ACT 2601, Australia
}

\section{A R T I C L E I N F O}

\section{Article history:}

Received 18 November 2013

Received in revised form

5 September 2014

Accepted 10 October 2014

Available online $\mathrm{xxx}$

\section{Keywords:}

Modelling

Biotic constraints

Agro-ecological modelling

Stripe rust

Puccinia striiformis

Farming systems modelling

DYMEX

APSIM

\begin{abstract}
A B S T R A C T
Farming systems frameworks such as the Agricultural Production Systems simulator (APSIM) represent fluxes through the soil, plant and atmosphere of the system well, but do not generally consider the biotic constraints that function within the system. We designed a method that allowed population models built in DYMEX to interact with APSIM. The simulator engine component of the DYMEX population-modelling platform was wrapped within an APSIM module allowing it to get and set variable values in other APSIM models running in the simulation. A rust model developed in DYMEX is used to demonstrate how the developing rust population reduces the crop's green leaf area. The success of the linking process is seen in the interaction of the two models and how changes in rust population on the crop's leaves feedback to the APSIM crop modifying the growth and development of the crop's leaf area. This linking of population models to simulate pest populations and biophysical models to simulate crop growth and development increases the complexity of the simulation, but provides a tool to investigate biotic constraints within farming systems and further moves APSIM towards being an agro-ecological framework.
\end{abstract}

Crown Copyright $\odot 2014$ Published by Elsevier Ltd. All rights reserved.

\section{Introduction}

Crop simulation modelling has progressed from specific crop or soil models, to linked crop and soil models, to the farming systems models that are common today (Moore et al., in this issue). This paper uses developments in the Agricultural Production Systems simulator (APSIM) (Holzworth et al., 2014; Keating et al., 2003) to present a case for linking a population modelling framework to a farming systems modelling framework. The combination enables the interaction of biotic constraints and the cropping system to be studied. However, this increased capability also increases complexity.

Farming systems models like APSIM, are better described as frameworks, because their software development allows the interconnection of the biophysical and management models to simulate processes within the farming system (Holzworth et al., 2010). Many of the new developments within the APSIM framework have been facilitated by the adoption of a Common Modelling

\footnotetext{
\& Special Issue on Agricultural Systems Modelling \& Software.

* Corresponding author.

E-mail address: Jeremy.Whish@csiro.au (J.P.M. Whish).
}

Protocol (CMP) (Moore et al., 2007) that has simplified the integration of components from other modelling tools. This work has enabled APSIM, a predominantly cropping model, to be combined with more complex grazing, pasture (Moore et al., 1997) and animal models (Freer et al., 1997) to more accurately represent the typical enterprises within a farming system (Holzworth et al., 2014). The linking of animal models to crop and pasture models was the initial step in accounting for the resource competition between different organisms within an APSIM simulation.

Simulating farming systems with APSIM has been of great benefit to agricultural production in Australia (Carberry et al., 2009a; Hochman et al., 2009) and in developing countries (Komarek et al., 2012; Lisson et al., 2010) as it has encouraged new developments, APSIM-ORYZA (Gaydon et al., 2012a, 2012b), APSIMOil Palm (Huth et al., 2014), and partnerships (Rosenzweig et al., 2013) that require the development of new capacity.

A success of APSIM is how it has helped researchers, farmers and consultants learn about their system (Carberry et al., 2009b) and more importantly identify how managing farm resources can improve production and profit (Murray-Prior et al., 2005). An increased understanding of the farming system has evoked new questions, which in turn, initiated further development within 
APSIM. The importance of stored soil water in rain-fed farming systems stimulated studies into the cost of lost grain by poor weed control in summer fallows (Hunt and Kirkegaard, 2011) and via the intercropping module (Carberry et al., 1996) competition between crops. A result has been the development of specific weed modules and competition studies (Deen et al., 2003; Robertson et al., 2001). The development of seed bank population models extended this work to investigations of the relationship between management and crop growth on the weed population. Initially, the seed bank models were constructed within APSIM's manager language (Grenz et al., 2006) but as the problem space became more complex alternatives were investigated.

A second seed bank model was developed in the visual modelling framework Vensim ${ }^{\mathrm{TM}}$ and linked to APSIM to evaluate farm management strategies to reduce weed seed banks (Smith et al., 2005). The Vensim-APSIM seed bank model was successfully used to investigate weed resistance in Australian rain-fed farming systems (Thornby and Walker, 2009; Thornby et al., 2010). However, the underlying structure of the Vensim ${ }^{\mathrm{TM}}$ seed bank model constrained this research, because of restrictions on the number of cohorts available, preventing it from modelling all the possible weed cohorts with their different genetic heritage positioned at different layers within the soil.

A conclusion from these studies was that when trying to combine agro-ecological models with population models a degree of compromise was required, either on the side of the agroecological model or the population model.

DYMEX (Sutherst and Maywald, 1998) is a detailed climatedriven, process-based, population cohort modelling framework. DYMEX has been used to model biotic constrains within agroecosystems, specifically insects (Yonow et al., 2004), diseases (Lanoiselet et al., 2002; White et al., 2004) and weed populations. A union between DYMEX and APSIM would provide a method to efficiently and generically integrate population models within the APSIM framework, reduce the current compromises (limited cohorts) and so make a further step in the transition of APSIM from a cropping systems to an agro-ecological model.

This paper will briefly summarise the key features of APSIM and DYMEX, describe how the generic communications framework underpinning APSIM has been used to couple the two models (Holzworth et al., 2010) and to demonstrate the application of this coupled model using interactions between stripe rust (Puccinia striiformis Westend) and wheat as a case study. The case study will highlight the aim of the DYMEX-APSIM link and how it can be used to model the affect of an increasing pest population (rust) on the growth and development of the crop (reduced leaf area).

\section{Linking a generic population model to a generic agro- ecological model}

\subsection{The Agricultural Production System Simulator (APSIM)}

The APSIM framework enables biophysical and management models to connect and interact. The success of these connections is a result of the development of the CMP that APSIM uses as the communications infrastructure, that allows models constructed in different software languages to communicate (Holzworth et al., 2010). For a more detailed description of APSIM its function, design and the models available see Holzworth et al. (2014) and the earlier paper of Keating et al. (2003).

\subsection{DYMEX}

DYMEX is a software package for building and running multicohort population models. Its original objective was to enable the building of mechanistic, process-based population models without the need for computer programing expertise (Sutherst et al., 2000). The package is divided into two parts, the model builder and the simulator. The builder allows the construction of the model from individual component modules, processes, and functions. The central component of a DYMEX model is the "lifecycle", which is composed of life stages though which each individual passes during its life (Maywald et al., 2007). All other modules and components exist to support the lifecycle. The builder itself uses a visual construction approach and libraries of pre-built modules and functions to simplify model construction.

The simulator is the second half of the DYMEX package. It allows models constructed in the builder to be processed. The simulator has two roles, firstly an engine that executes models that have been constructed in the builder, and secondly, a graphical user interface that allows parameters to be adjusted and outputs to be reported as graphs and tables.

\subsection{DYMEX-APSIM link}

To create a link between DYMEX and APSIM, the DYMEX simulation engine was incorporated into APSIM. This technically integrated approach (Knapen et al., 2013) was chosen over the alternatives (incorporating an APSIM simulation into the DYMEX simulator or writing a separate piece of linking software) for two reasons: firstly, this approach enables multi-point models (the ability to simultaneously simulate multiple points in space and the interactions between them, thus allowing the simulation of weed patch dynamics or disease movement between points) that link agro-ecological and population sub-models and secondly, the input and output facilities in APSIM are more suited to running and interpreting detailed biophysical models. A software interface to the DYMEX simulation engine (without its graphical user interface) was developed to implement DYMEX as a CMP-compliant component (Moore et al., 2007). Because APSIM simulations use the CMP, the DYMEX component executes with the rest of the APSIM simulation, it accepts information from other modules in the simulation (e.g. weather data drawn from standard APSIM climate files) and sends information (e.g. rust lesion growth) to other models (Fig. 1). The component interface was written to allow any model constructed with the DYMEX builder to be linked into APSIM.

Because DYMEX conceives of a population of organisms as a series of cohorts each of which can be in different life stages, the data structures used in DYMEX are complex. In the case study below, this information needed to be "unpacked" and transferred to the APSIM-Plant component, which deals in simpler data types. As a temporary measure, the APSIM-Plant component (the crop model in APSIM) was left unmodified and a script was written in the GRAZPLAN management component referred to as the CPI manager (the manager language used in the GRAZPLAN modelling framework) (Moore et al., in this issue) to perform the translation task.

Converting an existing DYMEX model to run in APSIM or to create an APSIM-enabled model from scratch requires three steps. Firstly, a DYMEX model is built in the DYMEX builder and the variables being shared with APSIM are defined. Secondly, the model is tested in the DYMEX simulator. Thirdly, the DYMEX-APSIM component is included within an APSIM simulation and directed to use the DYMEX text file created by the DYMEX builder. The variables being exchanged between APSIM and DYMEX are defined in the CPI management component so they can be queried or set at the correct time during a daily simulation cycle. Once connected, the DYMEX-APSIM component will display and allow modification of all writeable DYMEX variables. Further development of the DYMEX model can occur in the DYMEX builder and this will be 

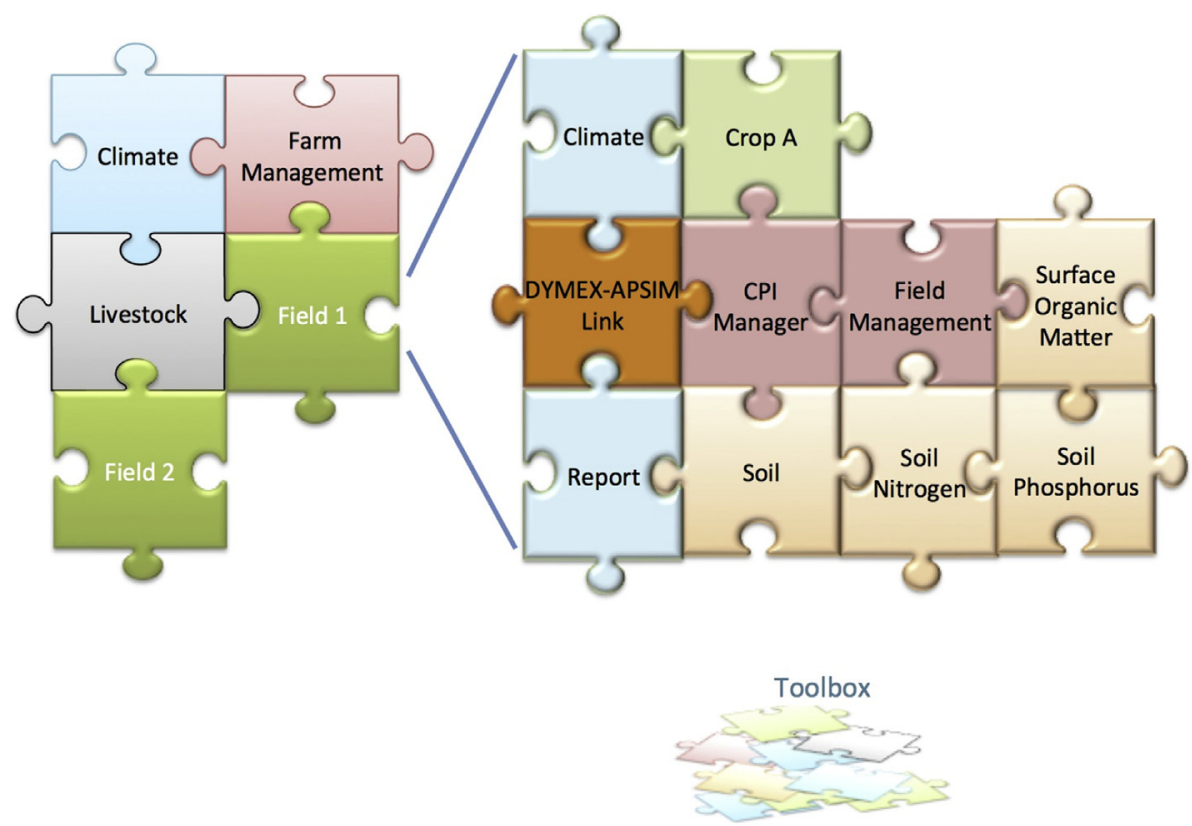

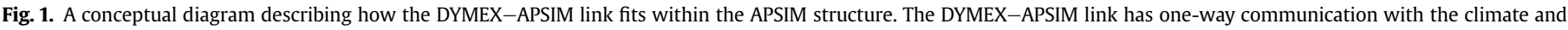
reporting models, and two-way communication with the CPI management component. Communication to all other APSIM models is via the CPI management component.

updated within APSIM, allowing a linked DYMEX model to be built and tested.

\section{Case study impact of stripe rust on wheat crops}

\subsection{Introduction}

An existing DYMEX model constructed to simulate the interactions between P. striiformis and wheat (White et al., 2004) was selected to test the DYMEX-APSIM link. This model had two lifecycles: one for wheat, which was based on a FORTRAN model developed for north western Victoria, Australia (O'Leary et al., 1996) and one for P. striiformis (White et al., 2004). To test the DYMEX-APSIM link we replaced the DYMEX-wheat lifecycle with APSIM-wheat. This case study outlines the process of connecting the wheat and stripe rust models and compares modelled output between the original DYMEX model and the new APSIM linked model. The new model was then used to simulate a four year stripe rust trial run in Wagga Wagga and Yanco, NSW Australia (Ellison and Murray, 1992).

\subsection{Linking the DYMEX stripe rust model and APSIM}

Wheat leaf area index (LAI) was the primary variable that linked the DYMEX model and APSIM. APSIM provided leaf area from the wheat model and DYMEX modelled the lifecycle and population dynamics of rust that was fed back to APSIM as a reduction in the green leaf area. Only the LAI was sent between the two models on receiving the new LAI from DYMEX the CPI-Manager would calculate a new reduced green leaf value and increased senesced leaf value for APSIM to start the next day.

Some other modifications were required to enable the DYMEX model to run within the APSIM framework. The original stripe rust model used a daily humidity value provided in the DYMEX climate file to calculate leaf wetness. APSIM climate files do not provide this value and humidity was calculated within DYMEX from vapour pressure using the DYMEX-weather module (Fitzpatrick, 1963; Sands and Hughes, 1976).

No other changes were made to the stripe rust model described by White et al. (2004). This model consisted of a life cycle divided into three life stages;

1. Spores: Spores were continually present, migrating in every day and ensuring the chance of infection was always present. Spores progressed to the infection stage if there was leaf area present, temperatures were within the correct range and greater than $1.6 \mathrm{~mm}$ of rain had fallen in a day.

2. Infection: Spores transferred to the infection stage underwent a period of development to simulate penetration of the leaf surface. The rate of infection responded to daily temperatures above a $5{ }^{\circ} \mathrm{C}$ threshold. Low relative humidity and the resistance rating of the wheat cultivar affected mortality during the infection stage.

3. Lesions: Growth of lesions occurred at a predefined rate depending on the resistance rating of the cultivar (Luo and Zeng, 1995) and was inhibited by the ratio of available uninfected leaf area. The total area of lesion determined the propagation of the infection with spores produced at a rate of 200 uredospores per $\mathrm{mm}^{2}$ of lesion area per day (Emge et al., 1975).

Comparison of lesion area and the proportion of leaf diseased between the two models were used to assess the success of the APSIM linked model. The sensitivity of the rust resistance parameter, the influence of daily migrating spore concentrations and the sensitivity to environmental conditions for the DYMEX-APSIM linked model were also examined. Following this testing the results of a four year stripe rust trial run in Wagga Wagga and Yanco, NSW Australia (Ellison and Murray, 1992) was used to test the value of the linked modelling system. No soil water measurements or final yields were reported by Ellison and Murray (1992) so estimates were made based on long-term simulations and discussions with local farmers and consultants. The varieties used in the experimental work are no longer grown and are not available in APSIM, so 
alternatives with similar phenological development were used within the APSIM simulation (Table 1).

\subsection{Case study results and discussion}

\subsubsection{A comparison of the DYMEX Wheat-Rust model and the DYMEX-APSIM linked model}

A comparison of the two models (Fig. 2a) showed similar results with some slight differences that could be observed due to differences in the timing of events. APSIM calculates LAI at the end of the day so the DYMEX rust model received this LAI value the following day causing a slight difference in the timing of lesion development.

Modelled lesion growth was similar when the model was run in APSIM and in DYMEX. However, the proportion of leaf diseased was different (Fig. 2b). This is not a failing of the DYMEX-APSIM link but rather a consequence of the difference in the way the O'Leary model (O'Leary et al., 1985) and APSIM-Wheat calculate leaf area once grain filling has commenced. Despite this difference, the total leaf area infected with rust is similar, though the timing of peak infection is different. A regression analysis between sowing and grain filling for the two outputs highlights the similarities between the two models with both lesion area and proportion of leaf diseased lying close to the $1: 1$ line. The regression equation for lesion area was $y=1$ (s.e. $=0.004) x+0.2$ (s.e. $=0.06$ ), $R^{2}=0.99$, $P<0.0001$, RMSD $=4.5$ and the proportion of leaf diseased was $y=1.4($ s.e. $=0.01) x-0.002$ (s.e. $=0.001), R^{2}=0.99, P<0.0001$, RMSD $=0.12$.

The aim of the DYMEX-APSIM link was to capture the influence of the DYMEX model on the growth and development of the APSIM-wheat model. The rust model combined crop leaf area and population growth of the rust to produce lesions on wheat leaves that effectively reduced the green leaf area of the crop (Fig. 3). Significant reductions in the leaf area index of the wheat cultivars that were very susceptible to rust (VS) demonstrate the feedback from the DYMEX model to the APSIM-wheat model.

The feedback between the two models was demonstrated further when the sensitivity to initial inoculum was tested (Fig. 4). Increasing the concentration of daily migrating inoculum reduced the crops leaf area index when conditions for rust development were high and the wheat variety was very susceptible.

Likewise, the sensitivity of the two models to different seasonal conditions can be observed in the different leaf area responses from five contrasting seasons (Fig. 5). The first two seasons (1984-1985) showed moderate to low levels of disease with the resistant

\section{Table 1}

The wheat cultivars used by Ellison and Murray (1992) and their resistance ratings and the varieties substituted in APSIM with the DYMEX resistance score. Wheat variety substitution was based on phenology and selections were based on similar alleles for photoperiod and vernalisation as presented by Eagles et al. (2009).

\begin{tabular}{|c|c|c|c|}
\hline $\begin{array}{l}\text { Observed } \\
\text { cultivar }\end{array}$ & $\begin{array}{l}\text { Resistance } \\
\text { rating }\end{array}$ & $\begin{array}{l}\text { APSIM } \\
\text { cultivar }\end{array}$ & $\begin{array}{l}\text { DYMEX } \\
\text { resistance } \\
\text { rating }\end{array}$ \\
\hline Avocet & VS & Krichauff & 5 \\
\hline Banks & $\mathrm{R}$ & Peake & 1 \\
\hline Bindawarra & $\mathrm{S}$ & Buckley & 4 \\
\hline Condor & MR & Sunvale & 2 \\
\hline Corella & $\mathrm{R}$ & Krichauff & 1 \\
\hline Egret & $\mathrm{S}$ & Krichauff & 4 \\
\hline Harrier & MS & None available & \\
\hline Millewa & MS & Livingston & 3 \\
\hline Olympic & MS & Gazelle & 3 \\
\hline Osprey & MR & Wylah & 2 \\
\hline Zenith & VS & None available & \\
\hline
\end{tabular}

$\mathrm{R}=$ Resistant $=1, \mathrm{MR}=$ Moderately Resistant $=2, \mathrm{MS}=$ Moderately Susceptible $=3$, $\mathrm{S}=$ Susceptible $=4, \mathrm{VS}=$ Very Susceptible $=5$ treatment producing a similar result to the no disease control and only the very susceptible treatment showing a reduction in leaf area. The 1986 season had poor conditions for disease development with no difference between the three treatments. The 1987 season experienced good conditions for disease development and both the resistant and very susceptible treatments lost leaf area, when compared to the no disease control. The final season (1988) shows the sensitivity of the rust model to climatic conditions. In this season a short period of favourable conditions caused a large number of spores to infect the leaves and commence producing lesions, however, before sporulation could occur a prolonged period of low humidity killed the lesions resulting in both the resistant and susceptible treatments having a similar leaf area. This low humidity period prevented the very susceptible treatment experiencing the high disease levels caused by repeat (polycyclic) infections of the plants. Had this low humidity period not occurred the results would have been similar to the previous season (1987, Fig. 5).

\subsubsection{Observed data modelling}

The experiment of Ellison and Murray (1992) assessed wheat cultivars with different rust resistance for percentage rust development. Their work was conducted over four seasons (1984-1987) at two sites, and in two years had both early and late sowings (1986, 1987). The 1984 and the 1987 seasons had major rust development on all cultivars while rust development in the 1985 and 1986 seasons varied. The Yanco site developed moderate to high rust levels in 1986 but in 1985 and at Wagga Wagga for both seasons the rust development was low. Their work used the model of Dennis (1987) to calculate the probability of infection and found the 1985 and 1986 seasons had the highest probability of infection, despite having the lowest development of disease. Their experiments relied on wind borne spores for infection in all years, however, infected plants were transplanted to both sites in 1986 to ensure infection occurred.

The DYMEX-APSIM linked model simulation of the high infection years (1984 and 1987) gave an adequate level of prediction. The model was able to initiate infections and generally grew rust populations that reduced the leaf area of the wheat plant to a similar level as those observed in the field. However the model tended to under predict the leaf area reduced by rust (Fig. 6)

The low disease years 1985-1986 were not simulated well by the model. Specifically, when the incidence of infection was less than $5 \%$. The majority of observed treatments that were scored as low infection ( $<5 \%$ infection) occurred when the model produced moderate to high infections. This suggests that the model does a good job of the growth and development of rust, but needs work on predicting initial infection especially when the incidence is low. This is a similar result to White et al. (2004) who also simulated moderate to high levels of diseased leaf in these low infection years. An explanation for this result could be the assumption in the model that inoculum is always present with 30,000 spores migrating into the system everyday. If the inoculum levels were low in the years that rust did not develop, then this may explain the discrepancy between the observed and predicted results.

The DYMEX-rust model has had limited development and testing, but has been valuable to highlight the DYMEX-APSIM link and the feedback between the two models. Future development of the rust model should examine the methods to supply inoculum, and reducing migrating inoculum once an infection has occurred. The mechanisms for infection and lesion development, which currently rely on rainfall and humidity calculated from the minimum temperature should also be examined. The use of a sub-daily 

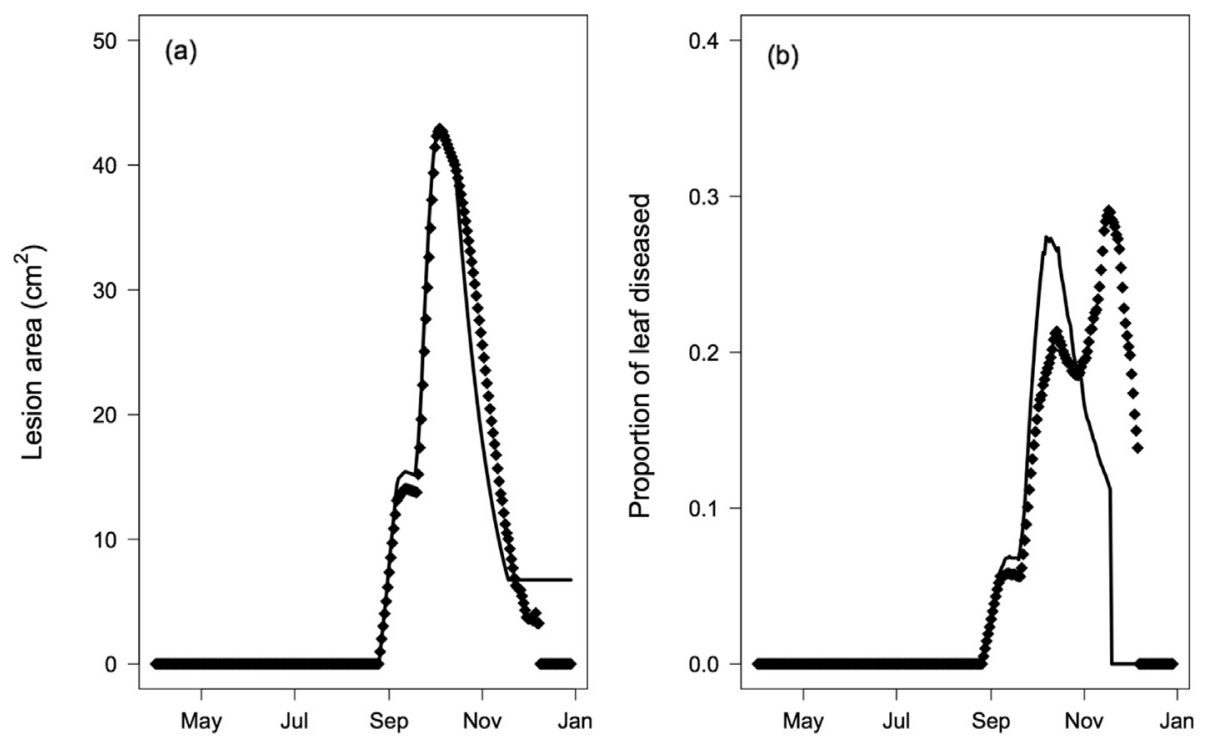

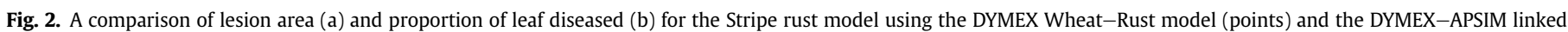
model (line). Both models simulated the 1985 season at Wagga Wagga as described by Ellison and Murray (1992).

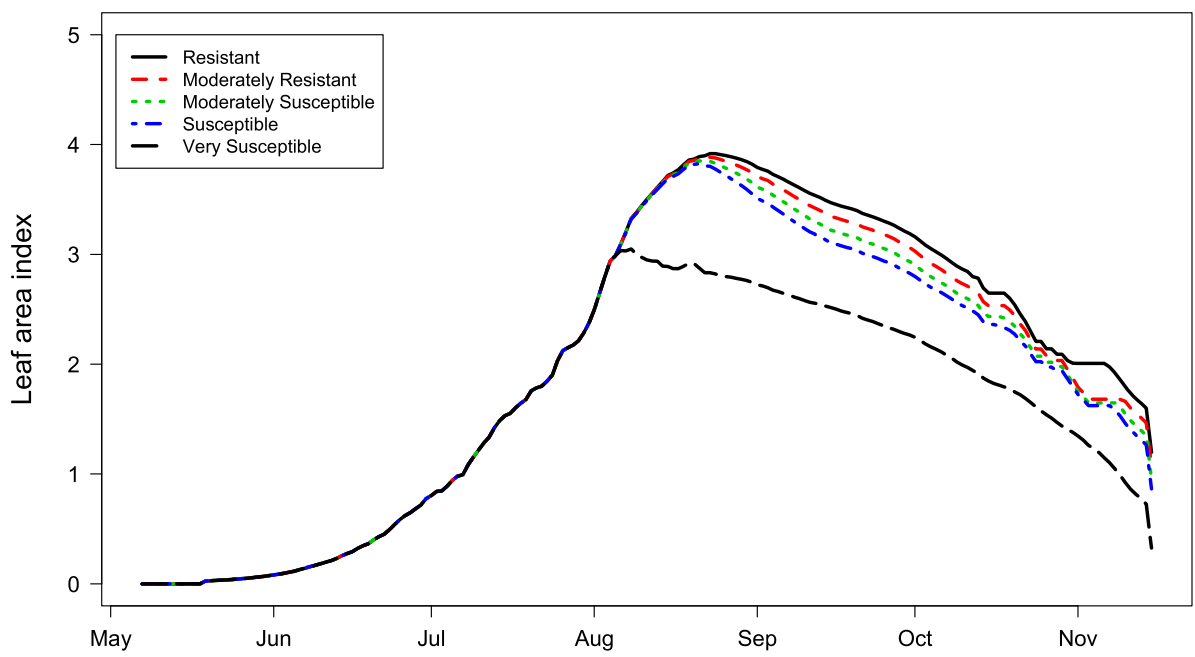

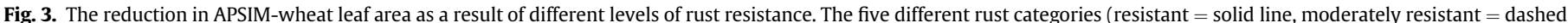
line, moderately susceptible $=$ dotted line, susceptible $=$ dash dot line, and very susceptible long dash line) had different effects on the final leaf area of the wheat crop.

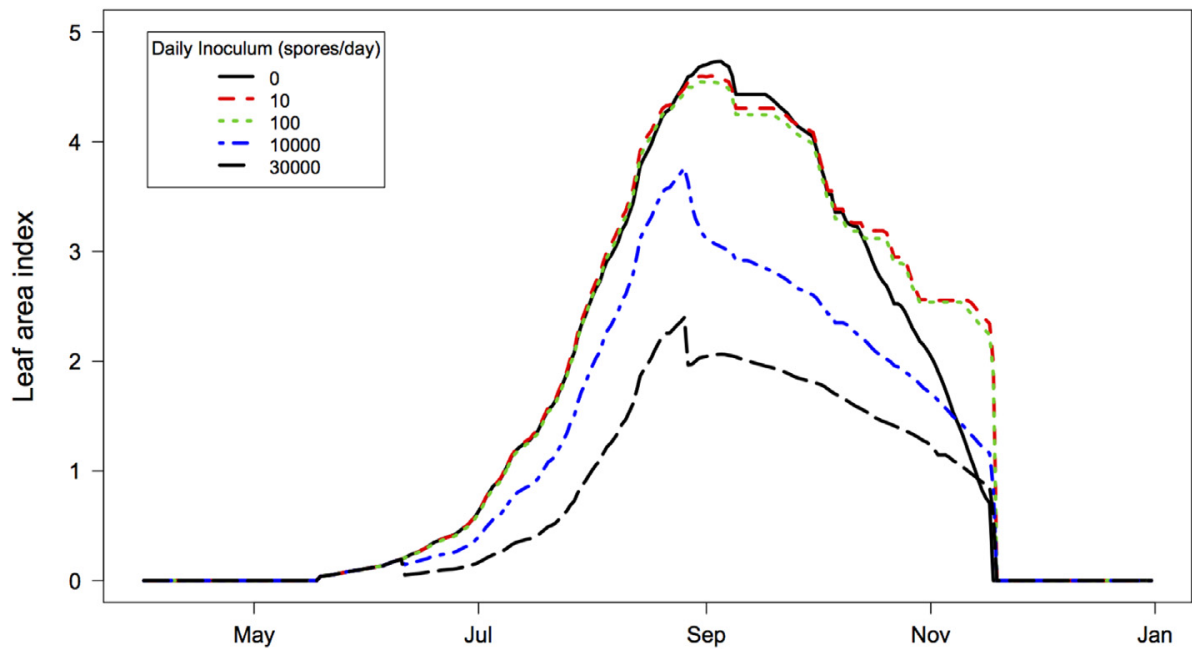

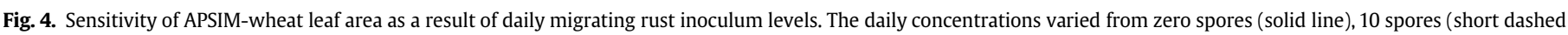
line), 100 spores (dotted line), ten thousand spores (dot dashed line) and thirty thousand spores (long dashed line). 


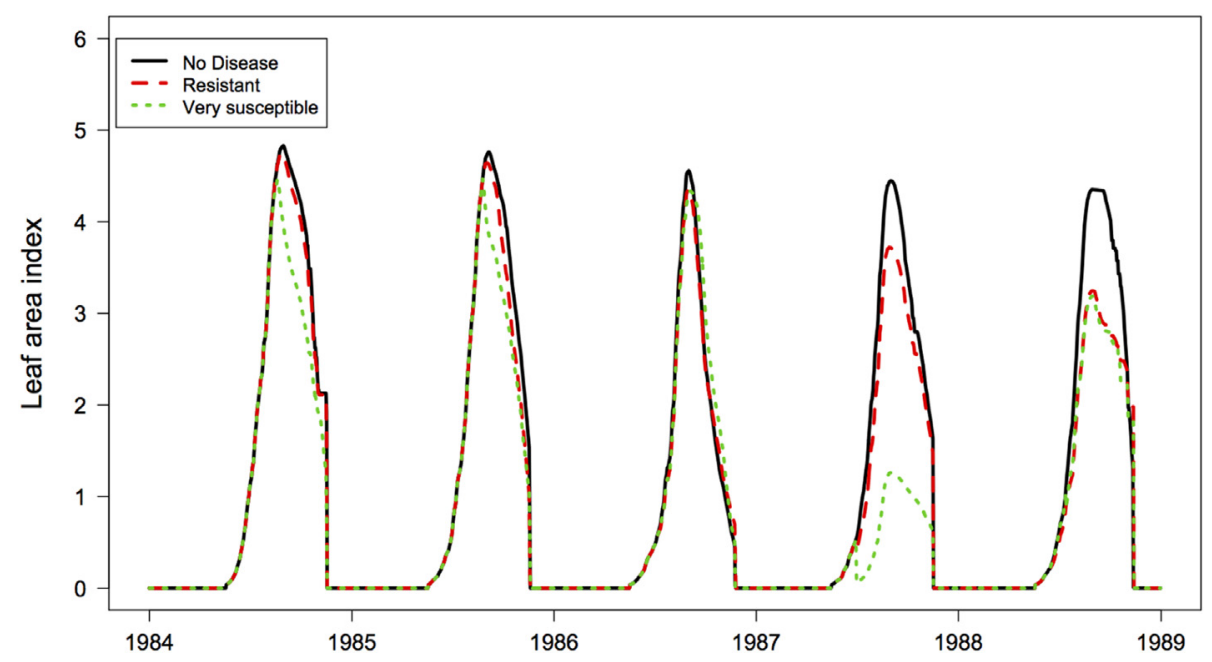

Fig. 5. The sensitivity of APSIM-wheat leaf area to rust development and cultivar rust resistance, over different seasonal climatic conditions.

leaf wetness model to drive infection and lesion growth might provide a more accurate simulation.

$$
\begin{aligned}
y & =0.7(\text { s.e. }=0.1) x+5.3(\text { s.e. }=7.2), R^{2} \\
& =0.46, P<0.0001, \text { RMSD }=44
\end{aligned}
$$

If the low disease incidence results ( $<5 \%$ diseased leaf) are removed the regression is $y=0.7$ (s.e. $=0.1) x+5$ (s.e. $=7$ ), $R^{2}=0.50, P<0.0001$, RMSD $=44$.

\section{Discussion}

This case study provided an example of how linking DYMEX to APSIM has increase the potential for new investigations of agroecological systems than by using APSIM alone. Although the DYMEX rust model had limited ability to predict the proportion of disease in all of the years examined, we demonstrate how to successfully combine such a model within the APSIM CMP framework and change the development of the wheat plant in response to the growing rust population. The polycyclic nature of rust and the high

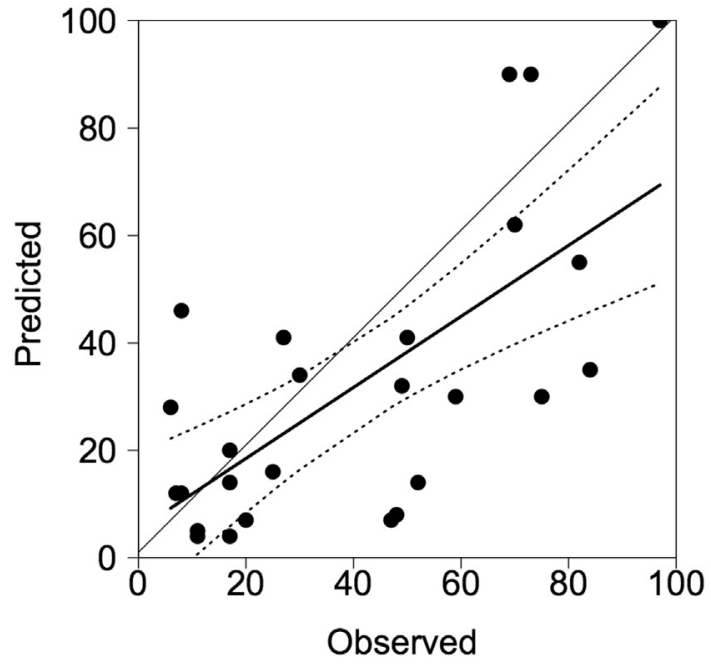

Fig. 6. The observed versus the DYMEX-APSIM predicted percentage leaf area reduced by rust from the experiments of Ellison and Murray (1992). The solid diagonal line is the 1:1 line, the bold line is the linear regression, and the broken lines are the $95 \%$ confidence limits. spore production rate (between 10 and 50 thousand per $\mathrm{cm}$ ) meant there were far more cohorts running in this DYMEX-APSIM linked simulation than in the seed bank model of Smith et al. (2005), overcoming one of the main limitations of that model. This highlights the importance of using a population model designed to efficiently run multiple cohorts.

\subsection{Areas of development for the DYMEX-APSIM link}

This current version of the DYMEX-APSIM link is sufficient, but as demand for this type of simulation increases, changes to streamline the linking procedure will be needed. Currently it is possible to develop models in the DYMEX builder and test them in APSIM. However, APSIM loads the DYMEX model on opening, so iterative development requires the constant opening and closing of the APSIM simulation. The DYMEX-APSIM link maps the climate data from APSIM directly to the DYMEX model, a future development of allowing other APSIM models to directly map to DYMEX will improve efficiency and avoid the two-stage step of using the manager script as an intermediary when transferring information between the models. These criticisms may seem minor, but the combining of DYMEX and APSIM currently requires a detailed knowledge of both models, so any efficiency gained by improving the mechanics of the linking operation will simplify the process.

\subsection{Increasing complexity by combining population models and agro-ecological models}

The combination of cropping systems models and biotic constraint models, be they population type models or static models, has previously been a compromise. Cropping systems models like APSIM have used simple disease or weed models (Chauhan et al., 2008, 2010; Grenz et al., 2006) while detailed process-based mechanistic population models, built with modelling tools like DYMEX, have made compromises in order to simulate the crop or soil components of the farming system (Kriticos et al., 2003; White et al., 2004; Young et al., 2002) Complexity, difficulty of parameterisation and the required detailed knowledge of the system are reasons for not combining detailed process based systems models with processed based population models (Colbach, 2010). However, the use of system frameworks such as APSIM, to supply farming system information, has eased the difficulty of parameterisation, simplifying the 
linking of these models. Once linked, the option for conducting in silico experiments as described by Colbach (2010) becomes a reality.

The point scale resolution of this linked model will be a limitation for migratory biotic constraints or when simulations move beyond the field, to the farm, catchment or region scale. However, with APSIM's multipoint capability, new cluster computing or an approach that uses these linked models to inform and develop meta models (Colbach, 2010) such as those used in catchment modelling (Golden et al., 2010; Norton et al., 2012) this DYMEX-APSIM link will help develop an increased understanding of the pest-farming system.

\subsection{Agro-ecological models and increased complexity}

The APSIM Initiative has enabled APSIM models to work across domains from the farmer to researcher (Carberry et al., 2009a). The key to this success is the delivery of specific information to each of these groups. Will this diverse user base continue when different population models are combined? One concern is the fundamental difference between the models comprising the farming systems frameworks and population models. The crop and soil models within frameworks like APSIM generally conserve mass (i.e. they attempt to maintain a mass balance) and are, therefore, constrained within defined limits that enable the system to be naturally reset at the end of the season. Population models, especially of weeds and pathogens, have the ability to become unstable if mortality triggers are not fully understood as population growth is often exponential, thus estimating population specific values is difficult. This is why probabilistic outputs are generally favoured for population models, compared to deterministic single value outputs used by crop and water balance models. However, this difference may provide a point of discussion, and the linked model a platform for collaboration between weed/ pest modellers and crop modellers. Allowing the transfer of information between the models and the two research groups.

The combining of detailed population models with crop models highlights the need for more knowledge on the pest crop interaction. Historically, when simple leaf area or phenology models were used to provide substrate for pest populations, the feedback of population growth on crop development was of little importance. However, to successfully link pest, crop and soil models, the mechanisms with which the pest damages the crop must be understood. If this mechanism is described correctly then the mass balance of the models can be maintained.

\section{Future directions}

The rust case study described was selected because it highlighted how an existing DYMEX model could be successfully linked to APSIM. As a result of this linking, new DYMEX models focussing on less transient diseases (Crown Rot, Fusarium pseudograminearum, pests (nematodes, Pratylenchus thornei) and weeds (wild radish, Raphanus raphanistrum) are being designed specifically to work with APSIM. Through these models, and the DYMEX-APSIM link a greater understanding of how farming systems affect pest populations and vice versa will be gained and APSIM will move further towards being an agro-ecological modelling framework.

\section{References}

Carberry, P.S., Adiku, S., McCown, R.L., Keating, B.A., 1996. Application of the APSIM cropping systems model to intercropping systems. In: Ito, C., Johansen, C., AduGyamfi, K., Katayama, K., Kumar-Rao, J.V.D.K., Rego, T.J. (Eds.), Dynamics of Roots and Nitrogen in Cropping Systems of the Semi-arid Tropics, pp. 637-648.

Carberry, P.S., Hochman, Z., Hunt, J.R., Dalgliesh, N., McCown, R.L., Whish, J.P.M., Robertson, M.J., Foale, M., Poulton, P.L., van Rees, H., 2009a. Re-inventing model-based decision support with Australian dryland farmers. 3. Relevance of
APSIM to commercial crops. Crop Pasture Sci. 60, 1044-1056. http://dx.doi.org/ 10.1071/CP09052.

Carberry, P.S., McCown, R.L., Hochman, Z., Dalgliesh, N., Foale, M., 2009b. Reinventing model-based decision support with Australian dryland farmers. 1. Changing intervention concepts during 17 years of action research. Crop Pasture Sci. 60, 1017-1030. http://dx.doi.org/10.1071/CP08455.

Chauhan, Y.S., Wright, G., Rachaputi, N.C., 2008. Modelling climatic risks of aflatoxin contamination in maize. Aust. J. Exp. Agric. 48, 358. http://dx.doi.org/10.1071/ EA06101.

Chauhan, Y.S., Wright, G., Rachaputi, R.C.N., Holzworth, D.P., Broome, A., Krosch, S., Robertson, M.J., 2010. Application of a model to assess aflatoxin risk in peanuts. J. Agric. Sci. 148, 341-351. http://dx.doi.org/10.1017/S002185961000002X.

Colbach, N., 2010. Modelling cropping system effects on crop pest dynamics: how to compromise between process analysis and decision aid. Plant Sci. 179, 1-13. http://dx.doi.org/10.1016/j.plantsci.2010.04.009.

Deen, W., Cousens, R.T., Warringa, J., Bastiaans, L., Carberry, P.S., Rebel, K., Riha, S., Murphy, C., Benjamin, L.R., Cloughley, C., Cussans, J., Forcella, F., Hunt, T., Jamieson, P., Lindquist, J., Wang, E., 2003. An evaluation of four crop: weed competition models using a common data set. Weed Res. 43, 116-129. http:// dx.doi.org/10.1046/j.1365-3180.2003.00323.x.

Dennis, J.I., 1987. Temperature and wet-period conditions for infection by Puccinia striiformis f. sp. tritici race 104E137A. Trans. Br. Mycol. Soc. 88, 119-121. http:// dx.doi.org/10.1016/S0007-1536(87)80194-8.

Eagles, H.A., Cane, K., Vallance, N., 2009. The flow of alleles of important photoperiod and vernalisation genes through Australian wheat. Crop Pasture Sci. 60, 646-657. http://dx.doi.org/10.1071/CP09014.

Ellison, P.J., Murray, G.M., 1992. Epidemiology of Puccinia striiformis f. sp. tritici on wheat in southern New South Wales. Crop Pasture Sci. 43, 29-41.

Emge, R.G., Kingsolver, C.H., Johnson, D.R., 1975. Growth of the sporulating zone of puccinia striiformis and its relationship to stripe rust epiphytology. Phytopathology 65, 679-681.

Fitzpatrick, E.A., 1963. Estimates of pan evaporation from mean maximum temperature and vapor pressure. J. Appl. Meteorol. 2, 780-792 doi:10.1175/1520$0450(1963) 002<0780$ :EOPEFM $>20$. CO 2

Freer, M., Moore, A.D., Donnelly, J.R., 1997. GRAZPLAN: decision support systems for Australian grazing enterprises-II. The animal biology model for feed intake, production and reproduction and the GrazFeed DSS. Agric. Syst. http:// dx.doi.org/10.1016/S0308-521X(96)00045-5.

Gaydon, D.S., Probert, M., Buresh, R.J., Meinke, H., Suriadi, A., Dobermann, A., Bouman, B., Timsina, J., 2012a. Rice in cropping systems-Modelling transitions between flooded and non-flooded soil environments. Eur. J. Agron. 39, 9-24. http://dx.doi.org/10.1016/j.eja.2012.01.003.

Gaydon, D.S., Probert, M., Buresh, R.J., Meinke, H., Timsina, J., 2012b. Modelling the role of algae in rice crop nutrition and soil organic carbon maintenance. Eur. J. Agron. 39, 35-43. http://dx.doi.org/10.1016/j.eja.2012.01.004.

Golden, H.E., Knightes, C.D., Cooter, E.J., Dennis, R.L., Gilliam, R.C., Foley, K.M., 2010. Linking air quality and watershed models for environmental assessments: analysis of the effects of model-specific precipitation estimates on calculated water flux. Environ. Model. Softw. 25, 1722-1737.

Grenz, J.H., Manschadi, A.M., deVoil, P.G., Meinke, H., Sauerborn, J., 2006. Simulating crop-parasitic weed interactions using APSIM: model evaluation and application. Eur. J. Agron. 24, 257-267. http://dx.doi.org/10.1016/j.eja.2005.10.002.

Hochman, Z., van Rees, H., Carberry, P.S., Hunt, J.R., McCown, R.L., Gartmann, A., Holzworth, D.P., van Rees, S., Dalgliesh, N., Long, W., Peake, A.S., Poulton, P.L., McClelland, T., 2009. Re-inventing model-based decision support with Australian dryland farmers. 4. Yield Prophet ${ }^{\circledR}$ helps farmers monitor and manage crops in a variable climate. Crop Pasture Sci. 60, 1057-1070. http://dx.doi.org/ $10.1071 / \mathrm{CP} 09020$.

Holzworth, D.P., Huth, N.I., de Voil, P.G., 2010. Simplifying environmental model reuse. Environ. Model. Softw. 25, 269-275.

Holzworth, D.P., Huth, N.I., deVoil, P.G., Zurcher, E.J., Herrmann, N.I., McLean, G., Chenu, K., van Oosterom, E.J. Snow, V.O., Murphy, C., Moore, A.D., Brown, H., Whish, J.P.M., Verrall, S., Fainges, J., Bell, L.W., Peake, A.S., Poulton, P.L., Hochman, Z., Thorburn, P.J., Gaydon, D.S., Dalgliesh, N., Rodriguez, D., Cox, H., Chapman, S., Doherty, A., Teixeira, E., Sharp, J., Cichota, R., Vogeler, I., Li, F.Y., Wang, E., Hammer, G.L., Robertson, M.J., Dimes, J.P., Whitbread, A.M., Hunt, J., van Rees, H., McClelland, T., Carberry, P.S., Hargreaves, J.N.G., MacLeod, N.D., McDonald, C.K., Harsdorf, J., Wedgwood, S., Keating, B.A., 2014. APSIM - evolution towards a new generation of agricultural systems simulation. Environ. Model. Softw. (in this issue).

Hunt, J.R., Kirkegaard, J.A., 2011. Re-evaluating the contribution of summer fallow rain to wheat yield in southern Australia. Crop Pasture Sci. 62, 915-929. http:// dx.doi.org/10.1071/CP11268.

Huth, N.I., Banabas, M., Nelson, P.N., Webb, M., 2014. Development of an oil palm cropping systems model: lessons learned and future directions. Environ. Model. Softw. http://dx.doi.org/10.1016/j.envsoft.2014.06.021 (in this issue).

Keating, B.A., Carberry, P.S., Hammer, G.L., Probert, M.E., Robertson, M.J., Holzworth, D.P., Huth, N.I., Hargreaves, J.N.G., Meinke, H., Hochman, Z., McLean, G., Verburg, K., Snow, V.O., Dimes, J., Silburn, D.M., Wang, E., Brown, S., Bristow, K., Asseng, S., Chapman, S., McCown, R.L., Freebairn, D.M., Smith, C., 2003. An overview of APSIM, a model designed for farming systems simulation. Eur. J. Agron. 18, 267-288. http://dx.doi.org/10.1016/S1161-0301(02)00108-9.

Knapen, R., Janssen, S., Roosenschoon, O., Verweij, P., de Winter, W., Uiterwijk, M. Wien, J.E., 2013. Evaluating OpenMI as a model integration platform across disciplines. Environ. Model. Softw. 39, 274-282. 
Komarek, A.M., McDonald, C.K., Bell, L.W., Whish, J.P.M., Robertson, M.J., MacLeod, N.D., Bellotti, W., 2012. Whole-farm effects of livestock intensification in smallholder systems in Gansu, China. Agric. Syst. 109, 16-24. http:// dx.doi.org/10.1016/j.agsy.2012.02.001.

Kriticos, D.J., Brown, J.R., Maywald, G.F., Radford, I.D., Sutherst, R.W., Mike Nicholas, D., Adkins, S.W., 2003. SPAnDX: a process-based population dynamics model to explore management and climate change impacts on an invasive alien plant, Acacia nilotica. Ecol. Model. 163, 187-208. http://dx.doi.org/10.1016/ S0304-3800(03)00009-7.

Lanoiselet, V., Cother, E.J., Ash, G.J., 2002. CLIMEX and DYMEX simulations of the potential occurrence of rice blast disease in south-eastern Australia. Austral. Plant Pathol. 31, 1-7. http://dx.doi.org/10.1071/AP01070.

Lisson, S., MacLeod, N.D., McDonald, C.K., Corfield, J., Pengelly, B., Wirajaswadi, L. Rahman, R., Bahar, S., Padjung, R., Razak, N., Puspadi, K., Dahlanuddin, Sutaryono, Y., Saenong, S., Panjaitan, T., Hadiawati, L., Ash, A., Brennan, L., 2010. A participatory, farming systems approach to improving Bali cattle production in the smallholder crop-livestock systems of Eastern Indonesia. Agric. Syst. 103, 486-497. http://dx.doi.org/10.1016/j.agsy.2010.05.002.

Luo, Y., Zeng, S.M., 1995. Simulation studies on epidemics of wheat stripe rust (Puccinia striiformis) on slow-rusting cultivars and analysis of effects of resistance components. Plant Pathol. 44, 340-349. http://dx.doi.org/10.1111/j.13653059.1995.tb02786.x.

Maywald, G.F., Kriticos, D.J., Sutherst, R.W., Bottomley, W., 2007. Dymex Model Builder Version 3: User's Guide. Hearne Scientific Software Pty. http:// dx.doi.org/10.1371/journal.pone.0040313.g006.

Moore, A.D., Donnelly, J.R., Freer, M., 1997. GRAZPLAN: decision support systems for Australian grazing enterprises. III. Pasture growth and soil moisture submodels, and the GrassGro DSS. Agric. Syst. 55, 535-582. http://dx.doi.org/10.1016/ S0308-521X(97)00023-1.

Moore, A.D., Holzworth, D.P., Herrmann, N.I., Brown, H.E., de Voil, P.G., Snow, V.O., Zurcher, E.J., Huth, N.I., 2014. Modelling the manager: representing rule-based management in farming systems simulation models. Environ. Model. Softw. (in this issue).

Moore, A.D., Holzworth, D.P., Herrmann, N.I., Huth, N.I., Robertson, M.J., 2007. The common modelling protocol: a hierarchical framework for simulation of agricultural and environmental systems. Agric. Syst. 95, 37-48. http://dx.doi.org/ 10.1016/j.agsy.2007.03.006.

Murray-Prior, R.B., Whish, J.P.M., Carberry, P.S., Dalgliesh, N., 2005. Lucerne improves some sustainability indicators but may decrease profitability of cropping rotations on the Jimbour Plain. Anim. Prod. Sci. 45, 651-663. http://dx.doi.org/ 10.1071/EA03164.

Norton, L., Elliott, J.A., Maberly, S.C., May, L., 2012. Using models to bridge the gap between land use and algal blooms: an example from the Loweswater catchment, UK. Environ. Model. Softw. 36, 64-75. http://dx.doi.org/10.1016/ j.envsoft.2011.07.011.
O'Leary, G.J., Connor, D.J., White, D.H., 1985. A simulation model of the development, growth and yield of the wheat crop. Agric. Syst. 17, 1-26. http:/ dx.doi.org/10.1016/0308-521X(85)90019-8.

O'Leary, G.J., O'Leary, G.J., Connor, D.J., 1996. A simulation model of the wheat crop in response to water and nitrogen supply: II. Model validation. Agric. Syst. 52, 31-55. http://dx.doi.org/10.1016/0308-521X(96)00002-9.

Robertson, M.J., Whish, J.P.M., Smith, F.P., 2001. Simulating competition between canola and wild radish. In: Proceedings of the Twelveth Aust. Res. Assembly on Brassicas, October, Geelong, Australia.

Rosenzweig, C., Jones, J.W., Hatfield, J.L., Ruane, A.C., Boote, K.J., Thorburn, P. Antle, J.M., Nelson, G.C., Porter, C., Janssen, S., Asseng, S., Basso, B., Ewert, F., Wallach, D., Baigorria, G., Winter, J.M., 2013. The Agricultural Model Intercomparison and Improvement Project (AgMIP): protocols and pilot studies. Agric. For. Meteorol. 170, 166-182. http://dx.doi.org/10.1016/ j.agrformet.2012.09.011.

Sands, P.. Hughes, R.D. 1976. A simulation model of seasonal changes in the value of cattle dung as a food resource for an insect. Agric. Meteorol. 17, 161-183.

Smith, F.P., Holzworth, D.P., Robertson, M.J., 2005. Linking icon-based models to code-based models: a case study with the agricultural production systems simulator. Agric. Syst. 83, 135-151. http://dx.doi.org/10.1016/j.agsy.2004.03.004.

Sutherst, R.W., Maywald, G.F., 1998. DYMEX modelling workshops: a national collaborative approach to pest risk analysis and IPM in Australia. Pest Manag. Future Chall. 2, 57-62.

Sutherst, R.W., Maywald, G.F., Russell, B.L., 2000. Estimating Vulnerability Under Global Change: Modular Modelling of Pests. In: Presented at the Agriculture Ecosystems \& Environment, pp. 303-319.

Thornby, D.F., Walker, S.R., 2009. Simulating the evolution of glyphosate resistance in grains farming in northern Australia. Ann. Bot. 104, 747-756. http:// dx.doi.org/10.1093/aob/mcp204.

Thornby, D.F. Walker, S.R., Whish, J.P.M., 2010. Modelling to Estimate Glyphostate Resistance Risk in Barnyard Grass in the Northern Australian Grain Region. Australian Weed Science Society, pp. 1-3.

White, N.A., Chakraborty, S., Murray, G.M., 2004. A Linked Process-based Model to Study the Interaction Between Puccinia striiformis and Wheat. In: Presented at the th International Crop Science Congress, Brisbane, Australia.

Yonow, T., Zalucki, M.P., Sutherst, R.W., Dominiak, B.C., Maywald, G.F., Maelzer, D.A., Kriticos, D.J., 2004. Modelling the population dynamics of the Queensland fruit fly, Bactrocera (Dacus) tryoni: a cohort-based approach incorporating the effects of weather. Ecol. Model. 173, 9-30. http://dx.doi.org/10.1016/S0304-3800(03) 00306-5.

Young, K., Kriticos, D.J., Gallagher, R., 2002. Towards a process based emergence model for wild radish. In: 13th Australian Weeds Conference: Weeds "Threats Now and Forever?," Sheraton Perth Hotel, Perth, Western Australia, 8-13 September 2002: Papers and Proceedings, pp. 266-269. 